
\title{
25 Research Square \\ Tetracarbonate melts and the fate of primordial carbon in the deep Earth
}

Valerio Cerantola ( $\nabla$ valerio.cerantola@xfel.eu )

European XFEL https://orcid.org/0000-0002-2808-2963

Christoph Sahle

ESRF

\section{Sylvain Petitgirard}

ETH,Department of Earth Sciences, Institute of Geochemistry and Petrology

\section{Min Wu}

Zhejiang University of Technology

\section{Stefano Checchia}

ESRF https://orcid.org/0000-0003-0499-4885

\section{Christopher Weis}

Technische Universität Dortmund

Marco Di Michel

ESRF - The European Synchrotron

\section{Gavin Vaughan}

European Synchrotron Radiation Facility

\section{Ines Collings}

ESRF - The European Synchrotron

\section{Róbert Arató}

Isotope Climatology and Environmental Research Centre

\section{Max Wilke}

Universität Potsdam

\section{Adrian Jones}

University College London

\section{Michael Hanfland}

The European Synchrotron

John Tse

University of Saskatchewan https://orcid.org/0000-0001-8389-7615

\section{Physical Sciences - Article}

Keywords: tetracarbonate melts, deep mantle, carbon 
Posted Date: May 13th, 2021

DOl: https://doi.org/10.21203/rs.3.rs-294216/v1

License: (9) This work is licensed under a Creative Commons Attribution 4.0 International License. Read Full License

Version of Record: A version of this preprint was published at Communications Earth \& Environment on March 17th, 2023. See the published version at https://doi.org/10.1038/s43247-023-00722-8. 


\section{Abstract}

Much of Earth's carbon is thought to have been stripped away from the silicate mantle by dense metalliciron to form the core ${ }^{1}$. However, recent studies ${ }^{2,3}$ suggest that a considerable part of it could have remained stranded in the deep mantle due to a change in its affinity to dissolve into iron metal-alloys at the extreme pressures and temperatures of the deep Earth. The underlying physical phenomena that would render carbon less siderophile at extreme conditions remain elusive. Here we describe the compaction mechanisms and structural evolution of a simple carbonate glass to deep mantle pressures by monitoring the evolution of the electronic state and atomic structure of the glass upon compression. Our new experiments demonstrate a pressure-induced change in hybridization of carbon from $s p^{2}$ to $s p^{3}$ starting at $40 \mathrm{GPa}$, due to the conversion of ${ }^{[3]} \mathrm{CO}_{3}{ }^{2-}$ groups into ${ }^{[4]} \mathrm{CO}_{4}{ }^{4-}$ units, which is completed at $\sim 112$ $\mathrm{GPa}$. The pressure-induced increase of carbon coordination number from three to four increases possibilities for carbon-oxygen interactions with lower mantle silicates and increased compatibility 4,5 . Tetracarbonate melts provide a mechanism for changing the presumed siderophile nature of deep carbon and instead imply storage of carbon in the deep mantle as a possible source for carbon-rich emissions registered at the surface in intra-plate and near-ridge hot spots ${ }^{6,7}$

\section{Main Text}

The nature and properties of carbonate melts at high pressures $(p)$ and temperatures $(T)$ may govern the exchange of carbon between the Earth's interior and the atmosphere. Because of their low densities and viscosities at shallow depths ( $<5 \mathrm{GPa}$ ), carbonate melts can mobilize carbon out of subducting slabs and can segregate rapidly from the source regions, making them active factors in crustal and sub-crustal processes ${ }^{8,9}$. The remarkable physical properties of carbonate melts, such as low viscosity ${ }^{10}$ and high electrical conductivity ${ }^{11}$, are best explained by the electronic structure of the $\mathrm{CO}_{3}{ }^{2-}$ groups that lack unpaired orbitals for covalent bonding, and thus are unable to polymerize ${ }^{12}$, unlike the $\mathrm{SiO}_{4}{ }^{4-}$ tetrahedron in silicate melts. However, the behavior of carbonate melts at greater depths remains unexplored, despite the changes in physical and chemical properties that could be induced from compression-driven structural transformations, as observed e.g. in silicate melts ${ }^{13-15}$. Indeed, melt properties directly reflect on the chemical partitioning in the Earth, especially during the core-formation stage where partial, or complete, mantle melting occurred through the formation of deep magma oceans (MO) which enabled the segregation and formation of the metallic core ${ }^{1}$. During this process, the growing metallic core stripped away elements from the silicate mantle depending on their affinity, or siderophile character, carbon among them. Two recent studies ${ }^{2,3}$ reported a substantial change in the carbon partition coefficient between silicates and metals $\left(D_{\text {Cmetal/silicate }}\right)$ at $p>40 \mathrm{GPa}$, suggesting that carbon becomes more lithophile at depth and concentrated in the deep mantle, e.g. entering the structure of silicate melts. However, the underlying physical phenomena that would render carbon less siderophile remain elusive. Here, we report the pressure-induced changes in the atomic and electronic structure of the carbonatitic glass $\mathrm{K}_{2} \mathrm{Mg}\left(\mathrm{CO}_{3}\right)_{2}$ (Methods), used as an analogue for carbonate melts ${ }^{14,15}$ up to pressures near the core 
mantle boundary (CMB). Our results provide experimental evidence for the change in $D_{C}$ in the Earth's lower mantle. We used a combination of synchrotron-based techniques, non-resonant inelastic X-ray scattering (XRS) at the oxygen K-edge and X-ray diffraction via pair distribution function (PDF) analysis, to monitor the evolution of the electronic structure and bond lengths upon compression of the glass (Methods). The interpretation of the experimental data is supported by ab initio Molecular Dynamic (AIMD) simulations and spectrum calculations based on solving the Bethe-Salpeter equation (Methods).

Figure 1 shows the oxygen K-edge XRS spectra for $\mathrm{K}_{2} \mathrm{Mg}\left(\mathrm{CO}_{3}\right)_{2}$ at pressures ranging from 1 atm (Fig. $1 \mathrm{~A}$ bottom) to $100 \mathrm{GPa}$ (Fig. 1A top). The peak near $534 \mathrm{eV}$, more pronounced at lower pressures, reflects the antibonding molecular orbital of the resonant $\mathrm{C}=0$ double bond associated with the $\mathrm{CO}_{3}$ planar unit, also known as $\pi^{\star}$ resonance ${ }^{16}$. At higher energies, above $538 \mathrm{eV}$, a second broader feature indicated as $\sigma^{\star}$ corresponds to the unoccupied $\mathrm{C}-\mathrm{O} \sigma^{*}$ antibonding orbitals. The most prominent spectral change in the oxygen K-edge with pressure is the disappearance of the $\pi^{*}$-resonance at $534 \mathrm{eV}$ (Fig. 1A,B), unambiguous evidence of the breakage of the $\mathrm{C}=0$ double bond. The integrated intensity of the $\pi^{*}$ feature as a function of pressure in Fig. $1 \mathrm{C}$ shows that this process occurs gradually. After an initial decrease between ambient conditions and $10 \mathrm{GPa}$, we observe a plateau in $\pi^{\star}$-spectral intensity and a subsequent almost linear decay starting at $\sim 40 \mathrm{GPa}$ until the highest pressure, extrapolation suggests a complete disappearance at ca. $112 \mathrm{GPa}$. Besides these prominent changes in the spectral shape, we observe a shift of spectral weight visible by a smooth intensity increase in the $\sigma^{\star}$-resonance at pressures above $80 \mathrm{GPa}$, evidenced as the emergence of a peak at $536 \mathrm{eV}$ in the spectral-difference plot (Fig. 1B). We associate the shift to general compaction around the $O$ atoms. Simulated XRS spectra based on atomic structural snapshots from AIMD simulations are shown as thin black lines in Fig. 1A, supporting our assessment of the formation of $s p^{3}$-hybridized ${ }^{[4]} \mathrm{CO}_{4}$ units at the expense of ${ }^{[3]} \mathrm{CO}_{3}$ (Extended Data Fig. 6 and 7).

The PDFs in Fig. 2A show individual peaks representing well-defined cation-anion coordination shells, the first three being C-O, Mg-O and K-O (Extended Data Fig. 10). Cation-cation and anion-anion peaks are located at larger distances (Extended Data Fig. 10). While Mg-O and K-O merge together upon compression, the first peak of the PDF (C-O) is well resolved up to the highest measured $p$-point. A detailed view of the PDFs in the vicinity of the $\mathrm{C}-\mathrm{O}$ bond, is shown in Fig. 2B. After the initial compaction of the $\mathrm{C}-0$ distance between ambient pressure and $33 \mathrm{GPa}$, the initial C-0 length is recovered at $46 \mathrm{GPa}$ and increases up to $85 \mathrm{GPa}$, where it decreases again until the highest studied pressure of $104 \mathrm{GPa}$ (Fig. 2 , Table 1). Above $85 \mathrm{GPa}$ the $\mathrm{C}-\mathrm{O}$ peak is also affected by a remarkable broadening at the FWHM, which shows that C-O distances at $104 \mathrm{GPa}$ vary between $0.98 \AA$ to $1.42 \AA$, (Table 1). Compared to crystalline tetracarbonates ${ }^{17}$, the $\mathrm{C}-\mathrm{O}$ average bond length at $85 \mathrm{GPa}$ of $1.323 \AA$ is similar to those reported for i.e. $\mathrm{Fe}_{4} \mathrm{C}_{3} \mathrm{O}_{12}$ at $74 \mathrm{GPa}(1.352 \AA)$ and $\mathrm{Fe}_{4} \mathrm{C}_{4} \mathrm{O}_{13}$ at $97 \mathrm{GPa}(1.337 \AA$ ). The expansion of the bonds to an average length similar to the $\mathrm{C}$-O distance in $\mathrm{CO}_{4}$-units in crystalline tetracarbonate clearly indicates that at $\sim 85 \mathrm{GPa}$ more than $50 \%$ of the $\mathrm{CO}_{3}$-groups have been converted to $\mathrm{CO}_{4}$-groups, confirming the conclusions drawn from the XRS results and AIMD simulations (Extended Data Fig. 6). In the same pressure interval, the Mg-0 bond expands to $1.98 \AA$ (Extended Data Fig. 8, Table 1), which suggests an 
increase of coordination environment to $7+$ at $104 \mathrm{GPa}$, from the initial $\sim 4.5$ at 1 bar $^{18}$. $\mathrm{K}-\mathrm{O}$ bonds show an almost linear compression, with a kink on the compression rate at $46 \mathrm{GPa}$, which coincides with the onset of formation of ${ }^{[4]} \mathrm{CO}_{4}$-groups. $\mathrm{C}-\mathrm{O}, \mathrm{Mg}-\mathrm{O}$ and $\mathrm{K}-\mathrm{O}$ distances extracted from the AIMD simulations confirm these compression trends (Extended Data Fig. 9, Supplementary Text 1).

Overall, the behavior of the carbonate glass at high pressures can be rationalized as follows (Supplementary Text 1):

1. 0 - 40/45 GPa: filling of voids (mainly the first $10 \mathrm{GPa}$ ), compaction with local atomic rearrangement and distortions.

2. $40 / 45-85 \mathrm{GPa}$ : breaking of $\mathrm{C}=0$ double bonds in ${ }^{[3]} \mathrm{CO}_{3}$-groups and formation of ${ }^{[4]} \mathrm{CO}_{4}$ Onset of polymerization in the glass.

3. $>85 \mathrm{GPa}$ : a fully polymerized framework structure with some local remnants of $\mathrm{CO}_{3}$-groups, up to ca. $112 \mathrm{GPa}$. Further compaction.

Table l. Statistical information on the fiting of the PDF peaks as a function of pressure.

\begin{tabular}{llll|c}
\hline $\mathbf{P}(\mathbf{G P a} \mathbf{)}$ & $\mathbf{C}-\mathbf{O}(\boldsymbol{\AA})$ & \multicolumn{1}{l}{$\mathbf{M g}-\mathbf{O}(\boldsymbol{\AA})$} & $\mathbf{K}-\mathbf{O}(\boldsymbol{\AA})$ & $\mathbf{C}-\mathbf{O}(\mathbf{F W H M})$ \\
\hline 0 & $1.243(2)$ & $2.097(2)$ & $2.848(6)$ & 0.2915 \\
$33(2)$ & $1.185(2)$ & $1.939(7)$ & $2.621(1)$ & 0.3372 \\
$46(3)$ & $1.236(1)$ & $1.937(3)$ & $2.471(2)$ & 0.3144 \\
$85(4)$ & $1.323(1)$ & $1.979(45)$ & $2.406(23)$ & 0.3709 \\
$104(4)$ & $1.191(3)$ & $1.982(8)$ & $2.381(3)$ & 0.4381 \\
\hline
\end{tabular}

Carbon distribution in the deep Earth is expected to depend fundamentally on the physicochemical properties of carbon-complexes in melts along with their buoyancy. While most of the primordial carbon has been stripped away from the primordial mantle during core formation, new estimates predict carbon concentration between 0.09(4) and 0.20(10) wt\% C in the core ${ }^{3}$, much lower than the $1 \mathrm{wt} \%$ previously assessed from cosmochemical and geochemical considerations ${ }^{19}$. Even with the lowest estimates, the core would still account for more than half of Earth's total carbon budget ${ }^{3,20}$, the other half being in the mantle. Today's reservoirs reflect the mobility of carbon during early Earth history, when a hotter and more vigorous mantle mixing was possible ${ }^{21}$. Our results indicate that a large amount of the $C$ present at depths $>1200 \mathrm{~km}$ could have stayed there, forming C-rich silicate melts in virtue of its ability to polymerize with $\left(\mathrm{CO}_{4}\right)^{4-}$ molecules or higher order oxy-carbon complexes ${ }^{4}$. The presence of oxidized Cspecies such as $\left(\mathrm{CO}_{3}\right)^{2-}$ or $\left(\mathrm{CO}_{4}\right)^{4-}$ groups in silicate melts even at reducing oxygen fugacity $\left(\mathrm{fO}_{2}\right)$ conditions is predicted by simulations $\mathrm{s}^{4,5}$ with carbon atoms having the ability to bond directly to $\mathrm{Si}(\mathrm{Si}-\mathrm{C})$, $\mathrm{C}(\mathrm{C}-\mathrm{C})$ or with $\mathrm{O}$ forming a number of different ionic complexes ${ }^{4}$. Carbonated-silicate melts are also predicted as a result of redox melting processes in the reduced mantle at the $\mathrm{CMB}^{22}$. Moreover, the 
reducing $\mathrm{fO}_{2}$ in the primordial $\mathrm{MO}$ was shown to increase over time as a consequence of delivering increased oxidized material from the outer disk and the redox reaction $\mathrm{SiO}_{2}+2 \mathrm{Fe}$ à $2 \mathrm{FeO}+\mathrm{Si}$ tending towards the right as pressures and temperatures increase (4 and refs in therein). Carbon could have also participated as a redox buffer and stabilized oxy-carbon complexes.

The increased polymerization has a strong effect on density and melt rheology. Density estimates indicate that adding up to $5 \mathrm{wt} \%$ of $\mathrm{CO}_{2}$ in a $\mathrm{MgSiO}_{3}$ melt at $\mathrm{CMB}$ conditions does not change the melt density sufficiently to make it buoyant with respect to the surrounding mantle ${ }^{5}$. Hence, silicate melts could efficiently sequester significant amounts of carbon and simultaneously preserve the local mechanical stability since they have been found to be denser than the surrounding environment ${ }^{5,14}$. Thus, it is conceivable that the carbon present in the lowermost part of the lower mantle would have reached mechanical stability as a constituent of dense silicate melts and remained confined there.

Deep primordial carbon reservoirs could explain distinct geochemical and geophysical signatures observed at depths and at the surface. Seismic images reveal the presence of two massive anomalous zones above the core, commonly known as large low velocity provinces (LLVPs), where seismic waves travel slowly. These provinces occupy an area of $\sim 30 \%$ of the CMB and are considered to be chemically distinct from the surrounding mantle, hence potentially formed by primordial or subducted materia| ${ }^{23}$ (Supplementary Text 2,3). LLVPs exhibit geographical correlation with hotspot volcanism at the surface, which commonly overlie the edges of the LLVPs, in locations known as ultralow-velocity zones (ULVZ) ${ }^{23-}$ 25 (Fig. 3). Recent tomographic work suggests the presence of broad conduits of reduced wave velocities beneath some prominent hotspots, extending from ULVZ at the CMB to roughly $\sim 1000 \mathrm{~km} \mathrm{depth}{ }^{26}$. The total carbon emissions (e.g. magmatic eruptions and degassing) at these hotspots, e.g. Hawaii, Iceland, and Samoa, are considered to have parental magmatic $\mathrm{CO}_{2}$ content of the source ranging between 3000 and 10000 ppm, whereas mid-ocean-ridge (MORBs), which principally sample the convecting upper mantle, around $600 \mathrm{ppm}^{6}$. Despite the high possible uncertainties in these estimates, hotspot mantle $\mathrm{CO}_{2}$ concentrations are regarded as distinctly higher than mantle concentrations in all MORB segments located $>1000 \mathrm{~km}$ from hotspots ${ }^{7}$. Thus, we suggest that carbon enrichment in the deep lower mantle is possible as localized viscous carbonated silicate melts- and carbonatitic melts. These melts might be stripped away by deep upwelling material to become incorporated in rising plumes ${ }^{23,27}$, from as deep as the CMB, possibly constituting the parental source of intraplate oceanic volcanism and related ocean island basalts (OIBs). Upon decompression and depolymerization these C-rich oxidized melts become increasingly less viscous and more buoyant. Once exhumed to depths $<1200 \mathrm{~km}$ mechanical factors, such as low melt density, high buoyancy and mantle convection, contribute to ascent these carbon-rich melts into the upper mantle and ultimately their degassing into the atmosphere (Fig. 3).

The change in the speciation of the oxy-carbon complexes that we measured at extreme pressure affects carbon partitioning in the Earth. Here, we bring compelling evidence for the mechanism behind the enhanced lithophile character of carbon at extreme conditions. This suggests that the deep lower mantle may be the largest reservoir for the carbon cycle connected to well-known surface processes. 


\section{References}

1. Wood, B. J., Walter, M. J. \& Wade, J. Accretion of the Earth and segregation of its core. Nature 441, 825-833 (2006)

2. Blanchard, I. et al. The Fate of Carbon During Earth's Core-mantle Differentiation. EarthArXiv, doi:10.31223/osf.io/9t7ps, (2019).

3. Fischer, R. et al. The carbon content of Earth and its core. Proceedings of the National Academy of Sciences 117, 8743-8749 (2020).

4. Ghosh, D. B. et al. Carbon-bearing silicate melt at deep mantle conditions. Scientific Reports 7, 848 (2017).

5. Solomatova, N. V., Caracas, R. \& Manning, C. E. Carbon sequestration during core formation implied by complex carbon polymerization. Nature Communications 10, 789 (2019).

6. Hauri, E. H. et al. "Carbon in the Convecting Mantle" in Deep Carbon (Cambridge University Press, Cambridge, ed. 1, 2020), pp. 40-65.

7. Le Voyer, $\mathrm{M}$. et al. Carbon fluxes and primary magma $\mathrm{CO}_{2}$ contents along the global mid-ocean ridge system. Geochemistry, Geophysics, Geosystems 20, 1387-1424 (2019).

8. Plank, T. \& Manning, C. E. Subducting Carbon. Nature 574, 343-352 (2019).

9. Poli, S. Carbon mobilized at shallow depths in subduction zones by carbonatitic liquids. Nature Geoscience 8, 633-636 (2015).

10. Kono Y. et al. Ultralow viscosity of carbonate melts at high pressures. Nature Communications 5, 5091 (2014).

11. Gaillard, F., Malki, M., lacono-Marziano, G., Pichavant, M. \& Scaillet, B. Carbonatite Melts and Electrical Conductivity in the Asthenosphere. Science 322, 1363-1365 (2008).

12. Jones, A. P., Genge, M. \& Carmody L. Carbonate melts and carbonatites. Reviews in Mineralogy and Geochemestry 75, 289-322 (2013).

13. Sanloup, C. et al. Structural change in molten basalt at deep mantle conditions. Nature 503, 104-107 (2013)

14. Petitgirard, S. et al. Fate of $\mathrm{MgSiO}_{3}$ melts at core-mantle boundary conditions. Proceedings of the National Academy of Sciences 112, 14186-14190 (2015).

15. Prescher, $\mathrm{C}$. et al. Beyond sixfold coordinated $\mathrm{Si}$ in $\mathrm{SiO}_{2}$ glass at ultrahigh pressures. Proceedings of the National Academy of Sciences 114, 10041-10046 (2017).

16. Stöhr, J. "Simmetry and Molecular Orbitals" in NEXAFS Spectroscopy (Springer-Verlag Berlin Heidelberg, 1992), pp. 48-78.

17. Cerantola, V. et al. Stability of iron-bearing carbonates in the deep Earth's interior, Nature Communications 8, 15960 (2017).

18. Ghosh, D. B., Karki, B. B. \& Stixrude, L. First-principles molecular dynamics simulations of $\mathrm{MgSiO}_{3}$ glass: Structure, density, and elasticity at high pressure. American Mineralogist 99, 1304-1314 
(2014).

19. Wood, B. J., Li, J. \& Shahar, A. Carbon in the core: Its influence on the properties of core and mantle. Reviews in Mineralogy and Geochemestry 75, 231-250 (2013).

20. Li, J., Chen, B., Mookherjee, M. \& Morar, G. "Carbon versus Other Light Elements in Earth's core” in Deep Carbon (Cambridge University Press, Cambridge, ed. 1, 2020), pp. 40-65.

21. Lee, C-T. A. et al. Upside-down differentiation and generation of a 'primordial' lower mantle. Nature 463, 930-933(2010).

22. Dasgupta, R. \& Hirschmann, M. M. The deep carbon cycle and melting in Earth's interior. Eart and Planetary Science Letters 298, 1-13 (2010).

23. Garnero, E. J., McNamara, A. K. \& S-H. Shim, Continent-sized anomalous zones with low seismic velocity at the base of Earth's mantle. Nature Geoscience 9, 481-489 (2016).

24. Helmberger, D., Wen, L. \& Ding, X. Seismic evidence that the source of the Iceland hotspot lies at the core-mantle boundary. Nature 396, 251-255 (1998).

25. Cottaar, S. \& Romanowizc, B. An unusually large ULVZ at the base of the mantle near Hawaii, Eart and Planetary Science Letters 355-356, 213-222 (2012).

26. French, S. W. \& Romanowizc, B. Broad plumes rooted at the base of the Earth's mantle beneath major hotspots. Nature 525, 95-99 (2015).

27. Ballmer, M. D. et al. Persistence of strong silica-enriched domains in the Earth's lower mantle. Nature Geoscience 10, 236-240 (2017).

\section{Declarations}

Acknowledgments: We acknowledge the ESRF for providing synchrotron radiation and technical support. C. Henriquet is gratefully acknowledged for providing technical support at beamline ID20. We are thankful to $\mathrm{C}$. Cavallari and M. Apollo for support during the first XRS experiment. We acknowledge R. Rüffer and A. Chumakov for providing the diamonds used in the experiments. WM thanks the support by the National Natural Science Foundation of China (51701180, U1802254, 51871201).

Author contributions: VC conceptualized the project. APJ contributed to selection of carbonate glass. VC, ChJS, and SP interpreted the results and wrote the manuscript with contributions of all authors. RA, SP, MW and VC synthesized the sample. VC, ChJS, SP, CW performed the XRS experiments. VC, SP, ChJS, SC, GV, MDM, MH, IC performed the XRD experiment. CW and CHJS analyzed XRS data. SC, GV, MDM and VC analyzed XRD data. MW and JT performed AIMD simulations. ChJS performed BSE calculations.

Corresponding author: correspondence to Valerio Cerantola.

Competing interests: Authors declare no competing interests. 
Additional information

Extended data is available for this paper.

Supplementary information is available for this paper.

Correspondence and requests for materials should be addressed to Valerio Cerantola.

Publisher's note: Springer Nature remains neutral with regard to jurisdictional claims in published maps and institutional affiliations.

\section{Methods}

\section{Sample selection and preparation}

Pure carbonate glass (Extended Data Fig. 1) with composition $\mathrm{K}_{2} \mathrm{Mg}\left(\mathrm{CO}_{3}\right)_{2}$ was prepared at the Bayerisches Geoinstitut (BGI) by melting a homogenous and stoichiometric (50:50) mixture of $\mathrm{K}_{2} \mathrm{CO}_{3}$ and $\mathrm{MgCO}_{3}$ powder in an externally heated rapid-quench cold-seal pressure vessel, at $1 \mathrm{kbar}$ and $700{ }^{\circ} \mathrm{C}$ for 12 h. The experiment was terminated by rapid in-situ quenching. High purity $(>99.9 \%) \mathrm{K}_{2} \mathrm{CO}_{3}$ was purchased from Alfa Aesar $\mathrm{GmbH}$, dried prior to preparation of the mixture at $110{ }^{\circ} \mathrm{C}$ and stored in a drying oven. High purity $\mathrm{MgCO}_{3}$ was kindly provided by the Natural History Museum of London (UK), and dried at $200{ }^{\circ} \mathrm{C}$ to ensure dehydration of the $\mathrm{Mg}$ carbonate hydrates.

$\mathrm{K}_{2} \mathrm{Mg}\left(\mathrm{CO}_{3}\right)_{2}$-glass was chosen for two reasons, 1 ) the high $\mathrm{Mg}$ content in the glass well reflect the high abundance of $\mathrm{Mg}$ in the Earth's interior, hence making it suitable for experiments looking at simplified natural systems, 2) it is the simplest carbonate-glass stoichiometry quenchable at ambient conditions (Supplementary Text 2).

\section{X-ray Raman Scattering}

The high pressure X-ray Raman scattering (XRS) spectroscopy experiments (non-resonant inelastic x-ray scattering) were performed at beamline ID20 of the ESRF - The European Synchrotron Radiation Facility (Grenoble, France) using the large solid angle spectrometer ${ }^{28}$. We used radiation from four consecutive U26 undulators that was monochromatized by a succession of a high heat-load Si(111) pre- and a $\mathrm{Si}(311)$ channel-cut post-monochromator. The monochromatic x-rays were focused onto a spot size of $10 \times 20 \mu \mathrm{m}^{2}$ at the sample position using a Kirkpatrick-Baez (KB) mirror system. The opening angles of the DAC allowed us to use spherically bent $\mathrm{Si}(660)$ analyzer crystals: six in the forward and six in the backscattering geometry, respectively. Signals from the forward and backscattering arrays were checked for consistency and averaged for momentum transfers of $2.3 \pm 0.1 \AA^{-1}$ in forward scattering and $9.5 \pm 0.1$ $\AA^{-1}$ in backscattering. The incident energy was scanned between values of 10.20 and $10.24 \mathrm{keV}$ in order 
to obtain energy losses in the vicinity of the oxygen K-edge. All averaged signals were area normalized in the loss-region between 528.0 and $557.0 \mathrm{eV}$. In all experiments we used BX90 DACs ${ }^{29}$ equipped with 0.5 $\mathrm{mm}$ thick miniature diamonds ${ }^{30}$ and $200 \mu \mathrm{m}$ and $120 \mu \mathrm{m}$ diamonds culet size. All diamonds had a 15 $\mu \mathrm{m}$ deep recess drilled in the middle of the culet in order to maximize the x-ray path length through the sample inside the pressure chamber for an increased signal. All data analysis was performed using the XRStools program package ${ }^{31,32}$ as described in Weis et al. ${ }^{33}$. The experimental pressure conditions were estimated offline before and after each XRS measurement based on the Raman signal of the diamonds ${ }^{34}$, with the reported pressures being an average of the two values, and their difference was used as the error estimate.

\section{X-ray Diffraction and Pair Distribution Function}

The high-pressure $x$-ray diffraction experiments were performed at beamlines ID $15 a^{35}$ and ID $15 b$ of the ESRF. Membrane cells with $120 \mu \mathrm{m}$ culets size provided by the ESRF Sample Environment Service-HP lab were used in both experiments. For each pressure point a new $\sim 50 \mu$ m-diameter bead of $\mathrm{K}_{2} \mathrm{Mg}\left(\mathrm{CO}_{3}\right)_{2}$ was placed in a wide-aperture membrane cell, fitted with Re gaskets and no pressure medium. For each measurement, both sample and background signals were measured separately and used to calculate the structure factors $S(Q)$, which were obtained by subtraction of the background from the sample patterns (Extended Data Fig. 2). Background measurements were taken on the DAC containing only the empty gasket after decompression back to ambient conditions, thus maintaining the same gasket thickness as the sample measurement at high pressure. Incident monochromatic $x$-ray beams with energies of $60 \mathrm{keV}$ $(\lambda=0.2066 \AA)$ and $33 \mathrm{keV}(\lambda=0.4126 \AA)$ were used for the experiments performed at ID15a and ID15b, respectively. The $x$-ray beam was focused down to $3 \times 3 \mu \mathrm{m}^{2}$ at ID15a using a Kirkpatrick-Baez mirror system (KB) and to $10 \times 10 \mu \mathrm{m}^{2}$ at ID15b using Compound Refractive Lenses (CRLs). Diffraction data were collected with a Dectris Pilatus3 X CdTe 2M detector at ID15a and a MAR555 image plate detector at ID15b. Pilatus3X and MAR555 detectors were placed at $250 \mathrm{~mm}$ and $260 \mathrm{~mm}$ from the sample. A 20 $\mu \mathrm{m}$ pinhole was mounted at the entrance of the DAC to cut background air scattering. The detectorsample distance and the detector tilt angle were calibrated using $\mathrm{LaB}_{6}$ and silicon standards for ID15a and ID15b, respectively. Contrary to the MAR555 detector, which was centered with respect to the transmitted direct beam, the Pilatus detector was off-centered, allowing a higher Q-range to be detected. The typical collection time was of $\sim 8$ minutes at ID15a and 30 minutes at ID15b. A comparison example between structure factors measured at ID15a and ID15b at 30 GPa are displayed in Extended Data Fig. 3. As one can notice, the two curves nearly coincide, and most importantly, the onset of the first and second sharp diffraction peaks, FSDP and SSDP respectively, coincide.

Because of the larger high quality Q-range obtained from structure factors measured at ID15a (larger detector placed off of the sample center, higher energy), we decided to calculate the x-ray Pair Distribution Functions (PDFs) only from those data. The structure factors collected at ID15b were used, together with 
those from ID15a, to perform analyses on the FSDP and SSDP, of the S(Q) (Extended Data Fig. 4 and 5). Data for PDF analysis were collected at each pressure in 128 exposures of $4 \mathrm{~s}$ each. Particular care was taken during cell loadings to ensure reproducible positions of the diamond Bragg reflections on the detector between sample and background measurements. For each sample dataset the median image was calculated and we subtracted the corresponding median background image. Azimuthal integration to yield $I(Q)$ diffraction patterns was done using pyFAl ${ }^{36}$. From each $I(Q)$ the PDF, $g(r)$, was calculated using PdfGetX $3^{37}$. The range of $Q$ for $g(r)$ calculations was $0.8 \leq Q \leq 12 \AA^{-1}$. In order to obtain a reliable PDF from weak, noisy signal, ad-hoc intensity weighting and smoothing of the $Q$-space input functions were used to remove artifacts such as e.g. ripples, associated with parasitic scatting, particularly generated by the tails of diamond peaks. While peak intensities might not be very precise due to the difficulties of estimating against an unknown background, i.e. consequence of DAC setup, the peak positions are considered to be correct. Thus, we explain the distinguished intensity drop of the C-O peak of the PDF at 104 GPa (Fig. 2) caused by the PDF generation process.

\section{Ab initio molecular dynamics simulations}

First-principles molecular dynamics (FPMD) calculations were performed using the Vienna Ab initio Simulation Package (VASP) ${ }^{38}$ based on the density functional theory. Effects of the core electrons were replaced by atomic projected augmented wave (PAW) potentials ${ }^{39}$. Valence electronic configurations of $3 s^{2} 3 p^{6} 4 s^{1}, 3 s 23 p^{6} 4 s^{2}, 2 s^{2} 2 p^{2}$ and $2 s^{2} 2 p^{4}$ were used for $K, M g, C$ and $O$ atoms, respectively. The PerdewBurke-Ernzerhof (PBE) exchange-correlation functional ${ }^{40}$ was used. The wave functions were represented by a plane-wave basis set with an energy cutoff of $495 \mathrm{eV}$. To generate the glass structure of $\mathrm{K}_{2} \mathrm{Mg}\left(\mathrm{CO}_{3}\right)_{2}$ at ambient pressure and ambient temperature, a supercell containing 176 atoms $\left(16 \mathrm{~K}_{2} \mathrm{Mg}\left(\mathrm{CO}_{3}\right)_{2}\right.$ formula units) was initially melted at $2000 \mathrm{~K}$ for $30 \mathrm{ps}$ with a time step of $1 \mathrm{fs}$ in the canonical ensemble (NVT). The Nose-Hoover thermostat was used to control the temperature. A single point was used for Brillouin zone sampling. Then the molten structure was gradually cooled to $300 \mathrm{~K}$ in $10 \mathrm{ps}$ and followed by a NVT $\mathrm{MD}$ run at $300 \mathrm{~K}$ for at least another $30 \mathrm{ps}$. Higher pressure glass structures were obtained by isotropically reducing the cell size step by step. Due to the limited cell size and time duration of the MD calculation, over-heating is usually needed for the occurrence of the structural transformation in such closed system. Thus, the high pressure structure (above $28 \mathrm{GPa}$ ) were annealed at $4000 \mathrm{~K}$ for $30 \mathrm{ps}$ and then quenched to $300 \mathrm{~K}$. To eliminate anisotropy in the stress tensors from the NVT calculation, the isothermal-isobaric ensemble (NPT calculation) was employed on the quenched glass structures for an additional 20 ps. In agreement with experimental observations, structural analysis of the atomic configurations show 4-fold C-O coordination starting to appear at pressures higher than $58 \mathrm{GPa}$. The amount of 3- and 4- coordinated C-0 are almost equal at $106 \mathrm{GPa}$ (Extended Data Fig. 6). At $145 \mathrm{GPa}$, the highest pressure considered here, 4-coordinated $\mathrm{C}-\mathrm{O}$ becomes dominant. Snapshots extracted from the NPT MD trajectories were used in the computation of the XRS spectra (Fig. 1A). 


\section{BSE spectral calculations}

All spectrum simulations were performed based on structural snapshots from the ab initio molecular dynamics simulation trajectories described in the previous sub-section using the Bethe-Salpeter Equation (BSE) method as implemented in the OCEAN code (Obtaining Core level Excitations using Ab initio methods and the NIST BSE solver) ${ }^{41,42}$. For each of the spectra presented in Figure 1, we used 10 snapshots at regularly spaced time intervals of a few ps and evaluated the $0 \mathrm{~K}$-edge for each of the 960 atoms for a total of 960 individual 0 K-edge spectra at each pressure point.

Ground state electronic densities and wave functions were calculated at the density functional theory (DFT) level using Quantum ESPRESSO ${ }^{43}$. All DFT calculations were performed within the local density approximation (LDA) to the exchange-correlation functional, and using norm conserving pseudopotentials taken from the ABINIT repository. A planewave energy cutoff of 70 Ry and Gammapoint sampling for the ground state electron density proved to be sufficient. The wave functions for the screening and BSE calculation were generated from a non-self-consistent-field calculation using a $2 \times 2 \times 2$ k-point mesh. We used projector augmented wave (PAW) ${ }^{44}$ reconstructed all electron wave functions for the calculation of core to valence transition matrix elements. The dielectric screening was evaluated in within a sphere centered around every scattering atom using the random phase approximation and using the Levine-Louie model dielectric function outside this sphere. Convergence of the final spectra with respect to the change over radius ${ }^{45}$ was confirmed. Final electron-hole scattering states are obtained by solving the BSE.

28. Huotari, S. et al. A large-solid-angle X-ray Raman scattering spectrometer at ID20 of the European Synchrotron Radiation Facility. Journal of Synchrotron Radiation 24, 521-530 (2017).

29. 29. Kantor, et al. BX90: A new diamond anvil cell design for X-ray diffraction and optical measurements. Review of Scientific Instruments 83, 125102 (2012).

30. Petitgirard, S. et al. Miniature diamond anvils for X-ray Raman scattering spectroscopy experiments at high pressure. Journal of Synchrotron Radiation 24, 276-282 (2017).

31. Sahle, C. J. et al. Planning, performing and analyzing X-ray Raman scattering experiments. Journal of Synchrotron Radiation 22, 400-409 (2015).

32. Sahle, C. J. et al. Improving the spatial and statistical accuracy in X-ray Raman scattering based direct tomography. Journal of Synchrotron Radiation 24, 476-481 (2017).

33. Weis, C. et al. Pressure driven spin transition in siderite and magnesiosiderite single crystals. Scientific Reports 7, 16526 (2017).

34. Akahama, Y. \& Kawamura, H. Pressure calibration of diamond anvil Raman gauge to $310 \mathrm{GPa}$. Journal of Applied Physics 100, 043516 (2006).

35. Vaughan, G. et al. ID15A at the ESRF, a beamline for high speed operando X-ray diffraction, diffraction tomography, and total scattering. Journal of Synchrotron Radiation 27, 515-528 (2020). 
36. Ashiotis, G. et al. The fast azimuthal integration Python library: pyFAl. Journal of applied crystallography 48, 510-519 (2015).

37. Juhás, P. et al. PDFgetX3: A rapid and highly automatable program for processing powder diffraction data into total scattering pair distribution functions. Journal of Applied Crystallography 46, 560-566 (2013).

38. Kresse, G. \& Furthmüller, J. Efficient iterative schemes for ab initio total-energy calculations using a plane-wave basis set. Physical review B 54, 16 (1996).

39. Kresse, G. \& Joubert, D. From ultrasoft pseudopotentials to the projector augmented-wave method. Physical review B 59, 1758 (1999).

40. Perdew, J. P., Burke, K. \& Ernzerhof, M. Generalized gradient approximation made simple. Physical review letters 77,18 (1996).

41. Vinson, J., Rehr, J. J., Kas, J. J. \& Shirley, E. L. Bethe-Salpeter equation calculations of core excitation spectra. Physical Review B 83, 11, 115106 (2011).

42. Gilmore, K. et al. Efficient implementation of core-excitation Bethe-Salpeter equation calculations. Computer Physics Communications 197, 109-117 (2015).

43. Giannozzi, P. et al. QUANTUM ESPRESSO: a modular and open-source software project for quantum simulations of materials. Journal of physics: Condensed matter 21, 39395502 (2009).

44. Kresse, G. \& Joubert, D. From ultrasoft pseudopotentials to the projector augmented-wave method. Physical review B 59, 3, 1758 (1999).

45. Levine, Z. H. \& Louie, S. G. New model dielectric function and exchange-correlation potential for semiconductors and insulators. Physical Review B 25, 10, 6310 (1982).

46. Golubkova, A., Merlini, M. \& Schmidt, M. W. Crystal structure, high-pressure, and high-temperature behavior of carbonates in the $\mathrm{K}_{2} \mathrm{Mg}\left(\mathrm{CO}_{3}\right)_{2}-\mathrm{Na}_{2} \mathrm{Mg}\left(\mathrm{CO}_{3}\right)_{2}$ join. American Mineralogist 100, 24582467 (2015).

\section{Figures}



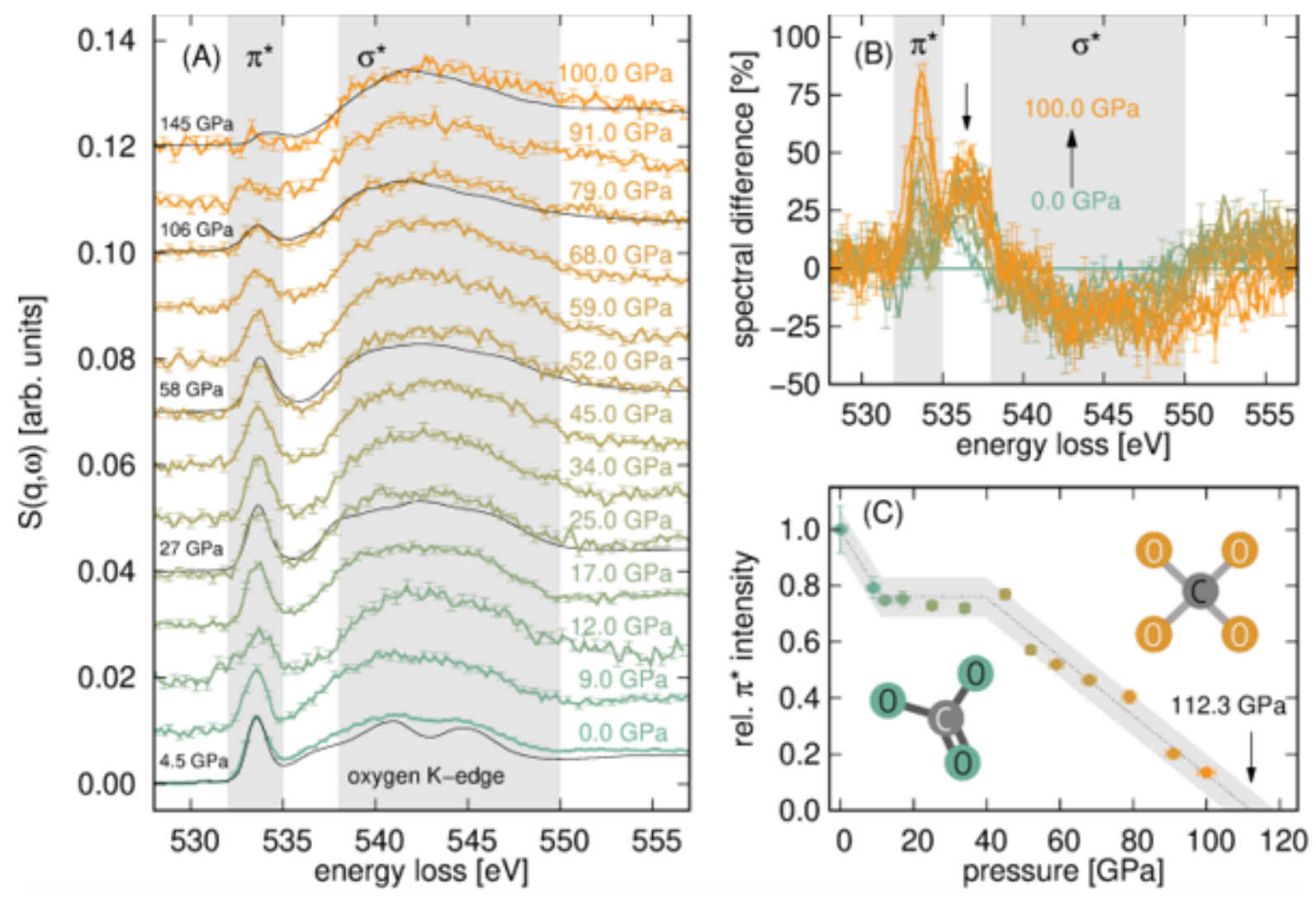

Figure 1

Experimental and simulated data from XRS spectroscopy. (A) Oxygen K-edge XRS spectra of $\mathrm{K} 2 \mathrm{Mg}(\mathrm{CO} 3) 2$ glass at pressures between 1 bar and 100 GPa. Simulated spectra are shown as thin black lines, the values on the left show the pressure at which the simulations were run. The simulated spectra are matched to the most similar experimental spectrum. (B) Spectral differences with respect to the ambient data. The regions of the $\pi^{\star}$ - and $\sigma^{\star}$-features are marked. (C) Integrated intensity of the $\pi^{\star}$ peak versus pressure. 

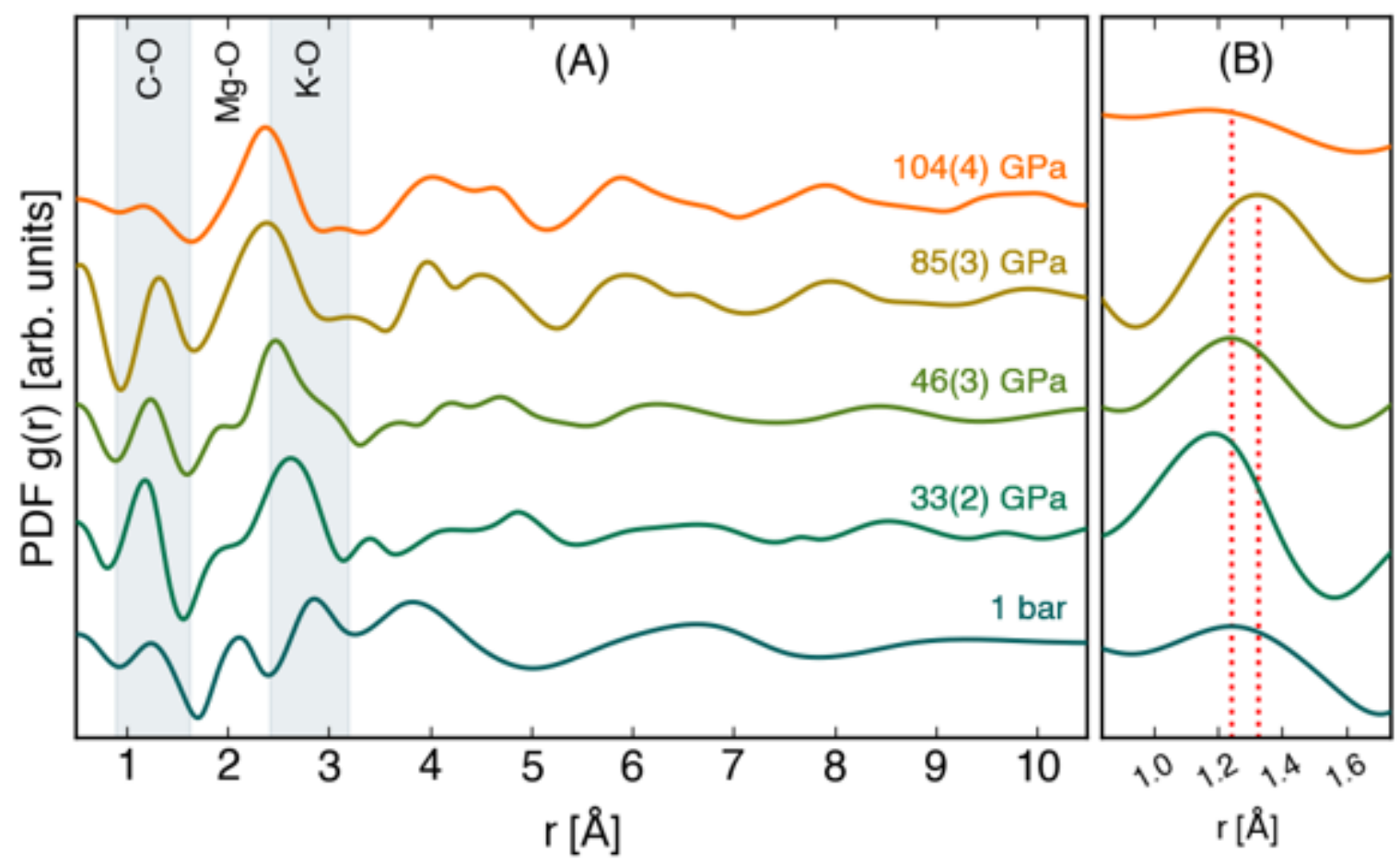

Figure 2

Pair distribution functions of $\mathrm{K} 2 \mathrm{Mg}(\mathrm{CO} 3) 2$ glass at different pressures. The PDFs were obtained by Fourier transforms of the structure factors (Extended Data Fig. 4A). (A) The grey shaded areas highlight the original position of $\mathrm{C}-\mathrm{O}$ and $\mathrm{K}-\mathrm{O}$ peaks ( $\mathrm{Mg}-\mathrm{O}$ in between) and emphasize their shift upon compression. (B) Close-up on the $\mathrm{C}-\mathrm{O}$ peak (representing the bond length distribution).
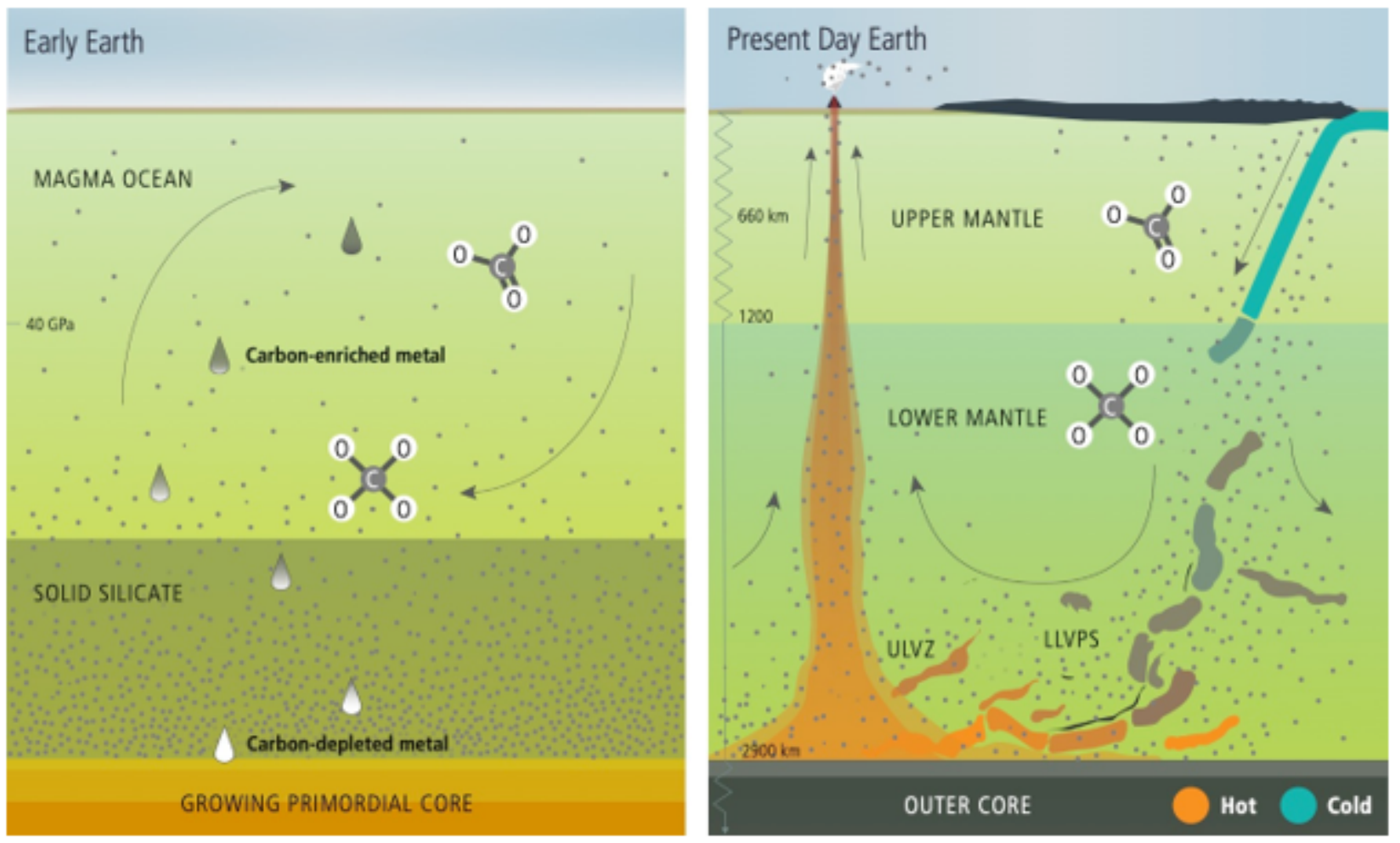


\section{Figure 3}

Distribution and cycling of carbon in the deep mantle during core formation (left) and in today's Earth (right). Carbon becomes less siderophile with depth and as a consequence is stranded in the lowermost lower mantle as tetracoordinated carbon in silicate melts. With the solidification and convective motions, primordial carbon was accumulated in specific regions at the CMB26 known as LLVPs and ULVZs. The latter are believed to be the original source of hotspot volcanisms23,26, thus primordial carbon trapped at the CMB could be the primary source of carbon emissions in these locations (Hawaii, Samoa, Pitcairn and many others). Image credit: Josh Wood.

\section{Supplementary Files}

This is a list of supplementary files associated with this preprint. Click to download.

- 3.supplementarycarboblassnature.docx

- ExtendedData.docx

- processedfiles.zip 